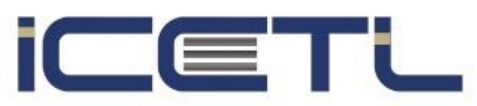

21-23 FEBRUARY, 2020

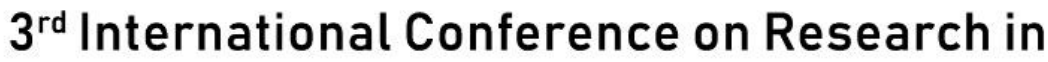 EDUCATION, TEACHING and LEARNING}

ROME, ITALY

\title{
21st Century Teacher Education
}

\author{
David Coulson \\ HLC/ Study group/ British Council
}

\begin{abstract}
Teacher educators play a fundamental role in the training of teachers of English as a Foreign Language to exploit digital technologies for teaching and learning. This presentation aims to explore the perceptions of teacher educators towards the adoption of technology and the knowledge base required. Furthermore, it explores the evolution of thinking on expertise and relates it to the effective exploitation of digital technologies for teaching and learning. The basis of the presentation is a study which was conducted through a series of interviews with recognised effective practitioners to build on previous research in other fields and to relate it to the field of EFL. The results and findings of the interviews provide interesting insights not only into the nature of 21 st century teaching expertise but also stimulate discussion regarding to what extent current EFL training courses are responsive to current trends in the area of education, and what could be done to improve them.

In researching into expertise in teaching and consequently the expertise required to use digital technology effectively not only the complexity of the problem became apparent but also the opportunities in what could potentially be an important time for education in English language teaching and learning. While it can be correctly argued that technology has always had a strong influence on education it has also been seen that there are certain defining moments that bring about change, the evidence in this research pointing to the fact that this may be one of those moments. Methods of communication and information are running ahead of us and the normalisation of digital technology in the classroom is governing and demanding a reassessment of existing models.

It is essential to include and elaborate upon both existing good practice and practitioners. The mantra here should be one of 'incorporation 'not 'transformation' in order to enable teachers to develop an integrated knowledge base of content, pedagogical knowledge and technological knowledge. This combined with the ability to adapt this knowledge to particular learners or situations through integrated training and support networks will enable teachers to incorporate rather than exclude. For scholars the next step which exists is engagement with the technology while at the same time avoiding some of the hype and being mindful of the challenges. (Weller 2013).

The findings from the interviews provide us with the stimulus and justification for further research, both in the area of teacher expertise, and also into the nature of current EFL training and the possibility for modifications to be made to their courses. The evidence points towards the fact that we are approaching a key moment in education and it is how we react to this in terms of combining the potential of digital technology to benefit education with the results of sound educational research that will map the next stage in the relationship between the two.
\end{abstract}

Keywords: Technology teacher education EFL 